\title{
25 Research Square \\ Mental Health Problems and Related Factors in Chinese University Students During the COVID-19 Pandemic
}

\section{Shuang-Jiang Zhou}

Beijing Huilongguan Hospital

Meng Qi

Chengde Medical University

Lei-Lei Wang

Beijing Huilongguan Hospital

Xing-Jie Yang

Beijing Huilongguan Hospital

Li-Gang Zhang

Beijing Huilongguan Hospital

\section{Rui Yang}

Capital Medical University

Jing-Xu Chen ( $\sim$ chenjx1110@163.com )

Beijing Huilongguan Hospital https://orcid.org/0000-0003-2395-6120

\section{Research Article}

Keywords: COVID-19; Depressive symptoms; Anxiety symptoms; Suicidal ideation; Related factors ; University students

Posted Date: August 17th, 2020

DOI: https://doi.org/10.21203/rs.3.rs-58137/v1

License: (c) (i) This work is licensed under a Creative Commons Attribution 4.0 International License. Read Full License 


\section{Abstract}

Background: The coronavirus disease-2019 (COVID-19) pandemic is a serious threat to global public health, including a wide range of metal health problems. Current research focuses mainly on mental health status and related factors among Chinese university students during the COVID-19 pandemic.

Methods: Data from 11133 participants was obtained through an online survey of university students in mainland China. Depressive and anxiety symptoms were assessed by the Patient Health Questionnaire-9 (PHQ-9), and the 7-item Generalized Anxiety Disorder Scale (GAD-7), respectively.

Results: In total, $37.0 \%$ of the subjects were experiencing depressive symptoms, $24.9 \%$ anxiety symptoms, $20.9 \%$ comorbid depressive and anxiety symptoms, and $7.3 \%$ suicidal ideation. Multivariable logistic regression analysis revealed an increased presence of mental health problems in female students, graduate students, and those with personal COVID-19 exposure. Living with family and awareness of COVID-19 were protective factors against depressive and anxiety symptoms. In addition, male, depressive and anxiety symptoms were risk factors for suicidal ideation. Living with family, graduate students, prevention and control measures and projections of COVID-19 trends were protective factors against suicidal ideation.

Conclusions: The findings underlined that the mental health of university students should be monitored, and provided important information for healthcare planning during the COVID-19 pandemic.

\section{Background}

Coronavirus disease-2019 (COVID-19) is an acute respiratory infectious disease, similar to severe acute respiratory syndrome (SARS) [1], which was first reported in Wuhan, the capital city of Hubei province, in December 2019. COVID-19 is characterized by rapid, widespread, and strong infectivity, and lack of specific treatment [2], and was declared an international public health emergency by the World Health Organization (WHO) [3]. This highly contagious infectious disease has caused public panic and mental health stress [4]. Currently, since the outbreak of COVID-19, a substantial proportion of children, adolescents, and adults report psychological problems, such as depression, anxiety, suicidality, disrupt sleep and behavioral problems [5-10]. Some experts especially highlighted the urgency and importance of evaluating and managing mental health problems during the COVID-19 pandemic [11-13].

University students undergo a critical transition as they become independent and responsible for their own health during university years [14], and experience higher psychological stress levels (e.g., exams, living away from family and financial hardships ) than their peers in the general population $[15,16]$. University years are a peak period for the first onset of common mental disorders, while the majority of lifetime cases begin before 24 years of age [16]. Many studies in recent years have indicated that the burdensome symptoms of depression and anxiety are highly prevalent among university students and have a significant impact on university students' functioning [17-19]. In addition, suicidal ideation are also common among university students [20]. University students' mental health problems have increased significantly during the outbreak of infectious diseases such as severe acute respiratory syndrome (SARS) or influenza H1N1 [21, 22].

During the outbreak of COVID-19, university students' education, including university studies and internship, was completed halted, which implies long hours at home and can lead to disordered rhythms of life and irregular sleep 
patterns. Moreover, the pandemic has brought the risk of infection and death. These may be traumatic experiences and have a psychological impact on this population. Metal health problems in university attracted attention in a recent study, which indicated that the prevalence of mild, moderate and severe anxiety was $21.3 \%$, $2.7 \%$, and $0.9 \%$ respectively [23]. In this study, only anxiety symptoms were evaluated using the 7 -item Generalized Anxiety Disorder Scale (GAD-7). Moreover, it was conducted in a medical university and sampled by cluster sampling, so it was postulated that the 7143 respondents were all medical university students. However, some previous findings suggested that medical students were more likely to have mental health problems than non-medical students when facing large-scale pandemic outbreaks [24-26]. Therefore, the type of mental disorders that are prevalent and how they are distributed among the population is unclear in university students during the COVID-19 pandemic.

Since Chinese university students have been exposed to a persistent source of distress during the public health emergency, it is imperative to evaluate and respond to their mental health issues. For this purpose, the prevalence and potential factors contributing to depressive and anxiety symptoms, suicidal ideation were detected.

\section{Methods}

\section{Subjects and sampling}

This cross-sectional study was conducted from March 1 to March 15, 2020, using an online survey to assess mental health problems. Inclusion criteria were full-time university students, including undergraduate and graduate students, living in mainland China, equal to or greater than 18 years of age. All participants were invited to complete a battery of online questionnaires through the Wenjuanxing platform.

This study was approved by the Institutional Review Board of Beijing HuiLongGuan Hospital. All the participants provided online informed consent to participate in the study.

\section{Assessment tools and procedure}

Personal COVID-19 exposure was defined as a person in compulsory isolation or under medical observation, after having been diagnosed with COVID-19 or having a history of close contact with COVID-19 patients. Students' awareness of COVID-19 (COVID-19 knowledge, prevention and control measures, projections of COVID-19 trends, and negative impacts on life) were collected through a questionnaire constructed by the authors of this study. In the first question, respondents were asked about their familiarity with information about prevention and control of COVID-19, ranging from 1 ("very unfamiliar") to 5 ("very familiar"). In the second question, respondents were asked if they had taken all the prevention and control measures against COVID-19 to avoid infection, ranging from 1 ("very consistent") to 5 ("very inconsistent"). The last question in the survey prompted respondents to describe their attitudes towards the projections of COVID-19 trends, ranging from 1 ("very pessimistic") to 10 ("very optimistic").

Depressive symptoms was screened using the Chinese version of the 9-item Patient Health Questionnaire (PHQ-9) [27]. The PHQ-9 is a self-assessment tool for depressive symptoms based on the American Diagnostic and Statistical Manual of Mental Disorders (DSM-IV), with responses for each item ranging from 0 (not at all) to 3 (nearly every day). The symptom severity is determined by the total score, with 5-9 being mild, 10-14 being moderate, $15-19$ being moderately severe, and $20-27$ being severe. 
Anxiety symptoms were screened using the Chinese version of the 7-item Generalized Anxiety Disorder Scale (GAD-7) [28], with symptom prevalence on a scale from 0 (not at all) to 3 (nearly every day). The symptom severity is determined by the total score, with 5-9 being mild, 10-14 being moderate, and 15-21 being severe.

Suicidal ideation among college students were screened by single item (item 9) of PHQ-9, which has participants response how often they have thoughts that they would be better off dead. Suicidal ideation is divided into four grades: from 0 (not at all) to 3 (nearly every day). The higher the level, the more serious the suicidal ideation.

\section{Statistical analysis}

The dataset was established using EpiData software version 3.1 (Odense, Denmark) and analyzed with SPSS version 24.0 (IBM SPSS, IBM Corp., Armonk, NY, USA). Categorical variables, expressed as percentages, were analyzed using a Chi-squared test. The same method was used to compare the difference between the groups with and without anxiety symptoms, with and without suicidal ideation. Logistic regression was used to explore the predictors of depressive or anxiety symptoms, and suicidal ideation. The level of significance was set at $p<$ 0.05 (two-sided).

\section{Results}

A total of 11372 participants, representing all 31 provincial-level regions of mainland China, completed the online questionnaires. After removing those answering less than three minutes or living abroad, 11133 participants (1835 years old, median = 21) from 31 provincial-level regions, except Macau and Hong Kong, were involved in the current study, giving a response prevalence of $97.9 \%$. Table 1 shows that $62.3 \%$ of the participants were female, $56.4 \%$ were urban residents, $90.3 \%$ were graduate students, $95.5 \%$ were living with their families, and $7.2 \%$ had exposure to COVID-19. 
Table 1

Socio-demographic characteristics and association with depressive and anxiety symptoms $(\mathrm{N}=11,133)$

\begin{tabular}{|c|c|c|c|c|c|c|c|c|c|c|c|}
\hline \multirow[t]{2}{*}{ Variables } & \multirow[t]{2}{*}{$\mathbf{n}$} & \multirow[t]{2}{*}{$\%$} & \multicolumn{3}{|c|}{ Depressive symptoms } & \multicolumn{3}{|c|}{ Anxiety symptoms } & \multicolumn{3}{|c|}{ Suicidal ideation } \\
\hline & & & $\mathbf{n}$ & $\%$ & $\mathbf{P}$ & $\mathbf{n}$ & $\%$ & $\mathbf{P}$ & $\mathbf{n}$ & $\%$ & $p$ \\
\hline Gender & & & & & $\begin{array}{l}< \\
0.001\end{array}$ & & & $\begin{array}{l}< \\
0.001\end{array}$ & & & 0.007 \\
\hline Male & 4,195 & 37.7 & 1,424 & 33.9 & & 956 & 22.8 & & 341 & 8.1 & \\
\hline Female & 6,938 & 62.3 & 2,695 & 38.8 & & 1,811 & 26.1 & & 469 & 6.8 & \\
\hline Region & & & & & 0.165 & & & 0.866 & & & 0.080 \\
\hline Urban resident & 6,284 & 56.4 & 2,360 & 37.6 & & 1,558 & 24.8 & & 481 & 7.7 & \\
\hline Rural resident & 4,849 & 43.6 & 1,759 & 36.3 & & 1,209 & 24.9 & & 329 & 6.8 & \\
\hline Grade & & & & & 0.003 & & & $\begin{array}{l}< \\
0.001\end{array}$ & & & 0.958 \\
\hline Undergraduates & 10,053 & 90.3 & 3,674 & 36.5 & & 2,477 & 24.3 & & 731 & 7.3 & \\
\hline $\begin{array}{l}\text { Graduate } \\
\text { students }\end{array}$ & 1,080 & 9.7 & 445 & 41.2 & & 320 & 29.6 & & 79 & 7.3 & \\
\hline $\begin{array}{l}\text { Living with } \\
\text { family }\end{array}$ & & & & & $<.001$ & & & $\begin{array}{l}< \\
0.001\end{array}$ & & & $\begin{array}{l}< \\
0.001\end{array}$ \\
\hline Yes & 10,628 & 95.5 & 3,850 & 36.2 & & 2,552 & 24.0 & & 711 & 6.7 & \\
\hline No & 505 & 4.5 & 269 & 53.3 & & 215 & 42.6 & & 99 & 19.6 & \\
\hline $\begin{array}{l}\text { COVID-19 } \\
\text { exposure }\end{array}$ & & & & & $<.001$ & & & $\begin{array}{l}<.001 \\
0.001\end{array}$ & & & $\begin{array}{l}< \\
0.001\end{array}$ \\
\hline Yes & 801 & 7.2 & 369 & 46.1 & & 272 & 34.0 & & 84 & 10.5 & \\
\hline No & 10,332 & 82.8 & 3,750 & 36.3 & & 2,495 & 24.1 & & 726 & 7.0 & \\
\hline Total & 11,133 & 100 & 4,119 & 37.0 & & 2,767 & 24.9 & & 810 & 7.3 & \\
\hline
\end{tabular}

A total of $37.0 \%$ participants experienced mild to severe depressive symptoms, $24.9 \%$ experienced mild to severe anxiety symptoms, and the comorbidity prevalence of depressive and anxiety symptoms was $20.9 \%$. In addition, $7.3 \%$ of the students had suicidal ideation. The nonparametric Mann-Whitney test was applied to determine statistically significant differences in age between students with and without anxiety symptoms $(P<0.001)$, but not between those with and without depressive symptoms $(P=0.07)$. And there was also no significant differences in age between students with and without suicidal ideation $(P=0.35)$. As shown in Table 1 , there were no differences in depressive and anxiety symptoms, suicidal ideation among students between regions. The proportion of depressive symptoms among female students was higher than male students (38.9\% versus $33.9 \%$; $26.1 \%$ versus $22.8 \%$ ). But the proportion of suicidal ideation for male students was higher than female students (8.1\% versus 6.8\%). Depressive and anxiety symptoms were more likely to occur in graduate students than in undergraduates ( $41.2 \%$ versus $36.5 \%$; $29.6 \%$ versus $24.3 \%$ ), but there was no difference between undergraduate and graduate students for suicidal ideation. The differences in depressive and anxiety symptoms, suicidal ideation between students living with and without their families were statistically significant (53.3\% versus $36.2 \%$; 
$42.6 \%$ versus $24.0 \% ; 19.6 \%$ versus $6.7 \%$ ). Students with COVID-19 exposure reported more depressive and anxiety symptoms, suicidal ideation than those without COVID-19 exposure (46.1\% versus $36.3 \%$; $34.0 \%$ versus $24.1 \%$; $10.5 \%$ versus $7.0 \%)$.

As shown in Table 2, compared to students with depressive symptoms, students without depressive symptoms had higher scores of COVID-19 knowledge, prevention and control measures, and projections of the COVID-19 trends, and lower scores of negative impacts on life. This differences were also observed between the students with and without anxiety symptoms, with and without anxiety symptom.

Table 2

The relationship between COVID-19 awareness and depressive and anxiety symptoms $(\mathrm{N}=11,133)$

\begin{tabular}{|c|c|c|c|c|c|c|c|c|c|c|c|}
\hline \multirow[t]{2}{*}{ Variables } & \multirow[t]{2}{*}{$\mathbf{n}$} & \multirow[t]{2}{*}{$\%$} & \multicolumn{3}{|c|}{ Depressive symptoms } & \multicolumn{3}{|c|}{ Anxiety symptoms } & \multicolumn{3}{|c|}{ Suicidal ideation } \\
\hline & & & $\mathbf{n}$ & $\%$ & $\mathbf{P}$ & $\mathbf{n}$ & $\%$ & $\mathbf{P}$ & $\mathbf{n}$ & $\%$ & $\mathbf{P}$ \\
\hline $\begin{array}{l}\text { COVID-19 } \\
\text { knowledge }\end{array}$ & & & & & $\begin{array}{l}< \\
0.001\end{array}$ & & & $\begin{array}{l}< \\
0.001\end{array}$ & & & $<.001$ \\
\hline Very unfamiliar & 128 & 1.1 & 66 & 51.6 & & 45 & 35.2 & & 23 & 18.0 & \\
\hline Unfamiliar & 1,606 & 14.4 & 674 & 42.0 & & 440 & 27.4 & & 132 & 8.2 & \\
\hline Neutral & 4,713 & 42.3 & 1,836 & 39.0 & & 1,203 & 25.5 & & 361 & 7.7 & \\
\hline Familiar & 3,777 & 33.9 & 1,290 & 34.2 & & 908 & 24.0 & & 226 & 6.0 & \\
\hline Very familiar & 909 & 8.2 & 253 & 27.8 & & 171 & 18.8 & & 68 & 7.5 & \\
\hline $\begin{array}{l}\text { Prevention and } \\
\text { control } \\
\text { measures }\end{array}$ & & & & & $\begin{array}{l}< \\
0.001\end{array}$ & & & $\begin{array}{l}< \\
0.001\end{array}$ & & & $\begin{array}{l}< \\
0.001\end{array}$ \\
\hline Very consistent & 202 & 1.8 & 68 & 33.7 & & 53 & 26.2 & & 22 & 10.9 & \\
\hline Consistent & 462 & 4.1 & 196 & 42.4 & & 462 & 27.1 & & 42 & 9.1 & \\
\hline Neutral & 899 & 8.1 & 409 & 45.5 & & 304 & 33.8 & & 103 & 11.5 & \\
\hline Inconsistent & 5,909 & 53.1 & 2,300 & 38.9 & & 2,536 & 26.0 & & 449 & 7.6 & \\
\hline Very inconsistent & 3,661 & 32.9 & 1,146 & 31.3 & & 749 & 20.5 & & 194 & 5.3 & \\
\hline $\begin{array}{l}\text { Projections of } \\
\text { COVID-19 trend }\end{array}$ & & & & & $<0.001$ & & & $\begin{array}{l}< \\
0.001\end{array}$ & & & $\begin{array}{l}<.001 \\
0.00\end{array}$ \\
\hline Very pessimistic & 99 & 0.9 & 49 & 49.5 & & 42 & 42.4 & & 19 & 19.2 & \\
\hline Pessimistic & 734 & 6.6 & 397 & 54.1 & & 306 & 41.7 & & 101 & 13.8 & \\
\hline Neutral & 2,660 & 23.9 & 1,162 & 43.7 & & 823 & 30.9 & & 266 & 10.0 & \\
\hline Optimistic & 6,434 & 57.8 & 2,209 & 34.3 & & 1,410 & 21.9 & & 373 & 5.8 & \\
\hline Very optimistic & 1,206 & 10.8 & 302 & 25.0 & & 186 & 15.4 & & 51 & 4.2 & \\
\hline
\end{tabular}

Table 3 shows the results of multivariable logistic regression models. There was an increased presence of depressive and anxiety symptoms in female students $\left(\mathrm{OR}_{\mathrm{D}}=1.24,95 \% \mathrm{Cl} 1.14-1.34 ; \mathrm{OR}_{\mathrm{A}}=1.21,95 \% \mathrm{Cl} 1.11-\right.$ 1.33), graduate students $\left(\mathrm{OR}_{\mathrm{D}}=1.14,95 \% \mathrm{Cl} 1.00-1.30 ; \mathrm{OR}_{\mathrm{A}}=1.18,95 \% \mathrm{Cl} 1.02-1.346\right)$, and those with COVID- 
19 exposure $\left(\mathrm{OR}_{\mathrm{D}}=1.42,95 \% \mathrm{Cl} 1.22-1.65 ; \mathrm{OR}_{\mathrm{A}}=1.51,95 \% \mathrm{Cl} 1.29-1.76\right)$. It was found that living with family $\left(\mathrm{OR}_{\mathrm{D}}=0.52,95 \% \mathrm{Cl} 0.44-0.63 ; \mathrm{OR}_{\mathrm{A}}=0.46,95 \% \mathrm{Cl} 0.38-0.55\right), \mathrm{COVID}-19$ knowledge $\left(\mathrm{OR}_{\mathrm{D}}=0.85,95 \% \mathrm{Cl} 0.81-\right.$ $\left.0.89 ; \mathrm{OR}_{\mathrm{A}}=0.92,95 \% \mathrm{Cl} 0.87-0.97\right)$, prevention and control measures $\left(\mathrm{OR}_{\mathrm{D}}=0.88,95 \% \mathrm{Cl} 0.84-0.92 ; \mathrm{OR}_{\mathrm{A}}=0.87\right.$, $95 \% \mathrm{Cl} 0.83-0.91)$, and projections of COVID-19 trends $\left(\mathrm{OR}_{\mathrm{D}}=0.71,95 \% \mathrm{Cl} 0.67-0.74 ; \mathrm{OR}_{\mathrm{A}}=0.67,95 \% \mathrm{Cl} 0.63-\right.$ $0.70)$ were protective factors against depressive and anxiety symptoms. As for suicidal ideation, multivariable logistic regression showed that depressive $(\mathrm{OR}=10.62,95 \% \mathrm{Cl} 7.84-14.38)$ and anxiety symptoms $(\mathrm{OR}=5.56$, $95 \% \mathrm{Cl} 4.53-6.81)$ were risk factors. And female students $(\mathrm{OR}=0.72,95 \% \mathrm{Cl} 0.61-0.84)$, graduate students (OR = $0.74,95 \% \mathrm{Cl} 0.57-0.97)$, living with family $(\mathrm{OR}=0.48,95 \% \mathrm{Cl} 0.37-0.64)$, prevention and control measures $(\mathrm{OR}=$ $0.86,95 \% \mathrm{Cl} 0.75-0.91)$, and projections of COVID-19 trends (OR $=0.83,95 \% \mathrm{Cl} 0.60-0.71)$. 
Table 3

Sociodemographic characteristics and COVID-19 awareness correlates with depressive and anxiety symptoms (N $=11,133)$

\begin{tabular}{|c|c|c|c|c|c|c|c|c|c|}
\hline \multirow[t]{2}{*}{ Variables } & \multicolumn{3}{|c|}{ Depressive symptoms } & \multicolumn{3}{|c|}{ Anxiety symptoms } & \multicolumn{3}{|c|}{ Suicidal ideation } \\
\hline & OR & $95 \% \mathrm{Cl}$ & $\mathbf{P}$ & OR & $95 \% \mathrm{Cl}$ & $\mathbf{P}$ & OR & $95 \% \mathrm{Cl}$ & $\mathbf{P}$ \\
\hline \multicolumn{10}{|l|}{ Gender } \\
\hline Male & 1 & & & 1 & & & 1 & & \\
\hline Female & 1.24 & $\begin{array}{l}1.14- \\
1.34\end{array}$ & $<.001$ & 1.21 & $\begin{array}{l}1.11- \\
1.33\end{array}$ & $<.001$ & 0.72 & $\begin{array}{l}0.61- \\
0.84\end{array}$ & $<.001$ \\
\hline \multicolumn{10}{|l|}{ Grade } \\
\hline Undergraduate & 1 & & & 1 & & & 1 & & \\
\hline Graduate & 1.14 & $\begin{array}{l}1.00- \\
1.30\end{array}$ & 0.051 & 1.18 & $\begin{array}{l}1.02- \\
1.36\end{array}$ & 0.025 & 0.74 & $\begin{array}{l}0.57- \\
0.97\end{array}$ & 0.028 \\
\hline \multicolumn{10}{|l|}{ Living with family } \\
\hline No & 1 & & & 1 & & & 1 & & \\
\hline Yes & 0.52 & $\begin{array}{l}0.44- \\
0.63\end{array}$ & $\begin{array}{l}< \\
0.001\end{array}$ & 0.46 & $\begin{array}{l}0.38- \\
0.55\end{array}$ & $<.001$ & 0.48 & $\begin{array}{l}0.37- \\
0.64\end{array}$ & $\begin{array}{l}< \\
0.001\end{array}$ \\
\hline \multicolumn{10}{|l|}{ COVID-19 exposure } \\
\hline No & 1 & & & 1 & & & 1 & & \\
\hline Yes & 1.42 & $\begin{array}{l}1.22- \\
1.65\end{array}$ & $<.001$ & 1.51 & $\begin{array}{l}1.29- \\
1.76\end{array}$ & $<.001$ & 1.17 & $\begin{array}{l}0.89- \\
1.52\end{array}$ & 0.262 \\
\hline \multicolumn{10}{|l|}{ Awareness of COVID-19 } \\
\hline COVID-19 knowledge & 0.85 & $\begin{array}{l}0.81- \\
0.89\end{array}$ & $<.001$ & 0.92 & $\begin{array}{l}0.87- \\
0.97\end{array}$ & 0.001 & 1.00 & $\begin{array}{l}0.91- \\
1.09\end{array}$ & 0.937 \\
\hline $\begin{array}{l}\text { Prevention and control } \\
\text { measures }\end{array}$ & 0.88 & $\begin{array}{l}0.84- \\
0.92\end{array}$ & $\begin{array}{l}< \\
0.001\end{array}$ & 0.87 & $\begin{array}{l}0.83- \\
0.91\end{array}$ & $<.001$ & 0.86 & $\begin{array}{l}0.75- \\
0.91\end{array}$ & 0.001 \\
\hline $\begin{array}{l}\text { Projections of COVID-19 } \\
\text { trend }\end{array}$ & 0.71 & $\begin{array}{l}0.67- \\
0.74\end{array}$ & $\begin{array}{l}< \\
0.001\end{array}$ & 0.67 & $\begin{array}{l}0.63- \\
0.70\end{array}$ & $\begin{array}{l}< \\
0.001\end{array}$ & 0.83 & $\begin{array}{l}0.60- \\
0.71\end{array}$ & $\begin{array}{l}< \\
0.001\end{array}$ \\
\hline \multicolumn{10}{|l|}{ Depressive symptoms } \\
\hline No & - & & & - & & & 1 & & \\
\hline Yes & - & & & - & & & 10.62 & $\begin{array}{l}7.84- \\
14.38\end{array}$ & $\begin{array}{l}< \\
0.001\end{array}$ \\
\hline \multicolumn{10}{|l|}{ Anxiety symptoms } \\
\hline No & - & & & - & & & 1 & & \\
\hline Yes & - & & & - & & & 5.56 & $\begin{array}{l}4.53- \\
6.81\end{array}$ & $\begin{array}{l}< \\
0.001\end{array}$ \\
\hline
\end{tabular}




\section{Discussion}

Emotional problems are the most common psychological symptoms in university students [29], which may further increase during public health emergencies [23]. This large-scale, cross-sectional, epidemiological, online study focused on evaluating depressive and anxiety symptoms of university students during the COVID-19 pandemic and explored possible related factors influencing them. This survey indicated three main findings. Firstly, among university students in mainland China, 37.0\% experienced depressive symptoms, $24.9 \%$ experienced anxiety symptoms, and $20.9 \%$ experienced comorbidity depressive and anxiety symptoms. Secondly, the female gender, being a graduate, and personal COVID-19 exposure were independent risk factors and living with family was an independent protective factor for developing depressive and anxiety symptoms. Thirdly, depressive and anxiety symptoms are negatively associated with the level of awareness of COVID-19.

Currently, there is no data on the prevalence of depressive symptoms in university students during the COVID-19 pandemic. Available data on the prevalence of anxiety symptoms was from a study conducted at a single medical university, which showed similar results to this study [23]. In general, the prevalence of depressive and anxiety symptoms demonstrated in this study is clearly much higher than in most previous studies during nonpandemic periods. For example, a meta-analysis, involving 39 studies with 32694 Chinese university students, indicated that the prevalence of depressive symptoms was $23.8 \%$ (95\% Cl: 19.9-28.5\%) [30]. In the case of anxiety symptoms, $10 \%$ of university and graduate students reported significant anxiety symptoms at some time during their school years $[29,31]$. However, a relatively high prevalence of depressive and anxiety symptoms has also been observed in individual studies [32]. On further analysis of the severity of mental health problems, it was found that mild depressive and anxiety symptoms were most common. In addition to anxiety and depression symptoms, college students' suicidal ideation during the COVID-19 epidemic should also be concerned. Studies have shown that during the COVID-19 epidemic, the public has a high rate of suicidal ideation due to factors such as unemployment, home isolation, anxiety, depression, and insomnia symptoms [10,33,34]. But there have been no studies of college students. So it is worth mentioning that, even though only $7.3 \%$ students had suicide ideation, more attention should be paid to students with these characteristics.

There is now sufficient evidence to state that the female gender is a reliable risk factor for depressive and anxiety symptoms $[5,17,32,35]$. The gender difference was verified in our study. But our study found female students is a protect factor for suicidal ideation, This is consistent with previous research on factors influencing suicide ideation among Chinese college students, it may be related to the great pressure placed on male college students by Chinese society [36]. Graduate students, in contrast to undergraduate ones, have more negative emotions. This might be explained by more profound stresses regarding economic, marital, academic, interpersonal, and employment concerns as a result of the pandemic. Although graduate students had more negative emotions, they had less suicidal ideation than undergraduates, this is not consistent with previous studies. Studies have shown that in the student population, for those older than 25 years old students, the suicide rate of students is significantly higher than that of students younger than 25 years old in college students. In the group of students aged 20 to 24, suicide rate of graduate students is higher than that of undergraduate students [37, 38]. In the present study, students living with family are related to lower risk of mental health problems, lower percentage of suicidal ideation. Some authors have demonstrated that family support, especially parental support, is very important and could effectively buffer the effects of high stress on anxiety symptoms and depressive symptoms, it also reduces suicidal ideation [39-42]. Conversely, the emotional loneliness resulting from being cut off from one's family is the strongest variable related to issues in mental health [43]. As predicted, COVID-19 exposure is 
closely related to bad moods. Individuals who were quarantined, irrespective of their wishes, suffered from isolation and directly faced the problems of infection, medical treatment, and even death $[44,45]$.

Good knowledge regarding infectious diseases may assist in the prevention of psychological problems [46]. More accurate COVID-19 knowledge significantly produced a lower likelihood of negative attitudes and potentially dangerous practices towards the pandemic [47], and reduced fear and panic [48]. Our findings supported this view and revealed COVID-19 knowledge as an independent protective factor for mental health among university students. Of course, it is important to provide specific up-to-date and accurate health information (e.g., treatment, local outbreak situation) about the outbreak [49]. Since the early stage of the COVID-19 pandemic, the Chinese government has provided essential COVID-19 knowledge to the public, every day, through media campaigns via television, radio, WeChat, Tik Tok and newspapers. However, it was found that only $42.1 \%$ students were familiar and $15.5 \%$ were unfamiliar with COVID-19 knowledge. Therefore, public health policy makers and health workers should recognize this target population for COVID-19 prevention training and health education.

Based on the pandemic characteristics of COVID-19, the Chinese government and public authorities made efforts to facilitate the implementation of pandemic prevention measures. The practices were very cautious in the Chinese population: decreased unnecessary outings, avoiding crowded places, wearing masks when going outside, and washing hands frequently [47]. Consistent with this, $87.0 \%$ students had taken all the prevention and control measures against COVID-19 to avoid infection in the current study. Moreover, our study results were in agreement with a previous study, which suggested that precautionary measures could reduce the psychological impact of the outbreak and levels of anxiety and depression [49-51]. According to this data, it is necessary to carry out targeted prevention and control measures and allocate health resources effectively.

During this survey period, the number of reported infection cases nationwide began to decline slightly, but the pandemic was spreading rapidly around the world and some imported cases occurred. Therefore, the public was urged to take more stringent preventive and control measures. Almost all students continued to stop their university studies and practice, and their range of activities was greatly restricted, which caused great inconvenience in their lives. Psychologically, when the living environment changes, people feel unsafe, uneasy, and anxious [52]. Long-term self-isolation can make people bored and prone to focus too much on negative pandemic information, which also increases the risk of mental health problems [53]. However, our finding that the majority of students had an optimistic attitude about overcoming this crisis was unexpected. The most likely explanation for this situation is due to the openness and transparency of data and the effective and standardized implementation of prevention and control work in China [54]. The optimistic attitude towards the prospects of COVID-19 could reduce depressive and anxiety symptoms because risk perception has a greater correlation with mental health [55]. Recently, the government actively promoted the resumption of work, production and education [56], which will further positively impact on mental health.

The key strengths of this study included the wide-ranging demographics and having the largest sample studied to date. In addition, it was the first study to investigate the prevalence of mental health among university students and its influence. However, there are also some limitations to this study. First, the study adopted the method of convenience sampling to recruit subjects, which may lead to a lack of sample representativeness and an imbalance of the sample distribution. Second, reporting bias may exist due to the nature of self-reported data, which may not always be consistent with the evaluation of mental health professionals. Third, all the data were collected in a cross-sectional survey, and therefore, causal relationships could not be established. Finally, the item 
9 of PHQ-9 was mainly used for the evaluation of suicide ideation. No professional questionnaire is used for the evaluation of suicide ideation, which may not be systematic and detailed enough.

In conclusion, the mental health status of university students has been affected during the COVID-19 pandemic, with a high prevalence of depressive and anxiety symptoms, suicidal ideation. The female gender, graduates, living with family, personal COVID-19 exposure and awareness of COVID-19 were related factors for depressive and anxiety symptoms. Although various psychological health services have been provided by the Chinese government through various channels, such as hotlines, online consultation and outpatient consultation [57], it is necessary to pay more attention to mental health among university students while combating COVID-19, and to early intervention regarding their psychological problems. In addition, our study showed that anxiety and depression symptoms are important risk factors for suicidal ideation. While paying attention to the anxiety and depression symptoms of university students, we should also pay attention to the students' suicidal ideation, and focus on the intervention of students with suicidal ideation.

\section{Declarations}

\section{Ethics approval and consent to participate}

Ethics Committee of Beijing HuiLongGuan Hospital approved the study.

\section{Consent for publication}

All authors agree to publish the paper.

\section{Availability of data and materials}

The data that support the findings of this study are available from the corresponding author upon reasonable request.

\section{Competing interests}

All authors have no conflicts of interest to declare.

\section{Funding}

This work was supported by Beijing Municipal Administration of Hospitals Clinical Medicine Development of Special Funding (XMLX201806); Capital Foundation of Medicine Research and Development (2018-3-2132); Special Foundation of Beijing Municipal Science \& Technology Commission (Z171100001017001).

\section{Authors' contributions}

The design of the questionnaire was completed by Shuang-Jiang Zhou, and Xing-Jie Yang; Meng Qi was responsible for the examination of the contents of the questionnaire; Li-Gang Zhang was responsible for the distribution and recovery of the questionnaire; Statistical analyses were completed by Lei-Lei Wang and Jing-Xu Chen; Rui Yang and Jing-Xu Chen received funding support for the research. Shuang-Jiang Zhou completed the first draft of this manuscript; Jing-Xu Chen designed the whole study, provided guidance and reviewed and submitted the article. All authors have read and agreed with the published version of the manuscript. 


\section{Acknowledgments}

We thank all of subjects who participated in this study. We would like to thank Editage (www.editage.cn) for English language editing.

\section{References}

1. Wang C, Horby PW, Hayden FG, Gao GF (2020) A novel coronavirus outbreak of global health concern. Lancet 395 (10223):470-473. doi:S0140-6736(20)30185-9

2. Chan JF-W, Yuan S, Kok K-H, To KK-W, Chu H, Yang J, Xing F, Liu J, Yip CC-Y, Poon RW-S, Tsoi H-W, Lo SK-F, Chan K-H, Poon VK-M, Chan W-M, Ip JD, Cai J-P, Cheng VC-C, Chen H, Hui CK-M, Yuen K-Y (2020) A familial cluster of pneumonia associated with the 2019 novel coronavirus indicating person-to-person transmission: a study of a family cluster. The Lancet 395 (10223):514-523. doi:10.1016/s0140-6736(20)30154-9

3. Organization $\varangle \mathrm{WH}$ (2020) WHO Director-General's statement on IHR Emergency Committee on Novel Coronavirus (2019-nCoV). https://www.who.int/dg/speeches/detail/who-director-general-s-statement-on-ihremergency-committee-on-novel-coronavirus-(2019-ncov). Accessed 30 January 2020

4. Bao Y, Sun Y, Meng S, Shi J, Lu L (2020) 2019-nCoV epidemic: address mental health care to empower society. Lancet 395 (10224):e37-e38. doi:10.1016/S0140-6736(20)30309-3

5. Zhou SJ, Zhang LG, Wang LL, Guo ZC, Wang JQ, Chen JC, Liu M, Chen X, Chen JX (2020) Prevalence and socio-demographic correlates of psychological health problems in Chinese adolescents during the outbreak of COVID-19. Eur Child Adolesc Psychiatry. doi:10.1007/s00787-020-01541-4

6. Liu JJ, Bao Y, Huang X, Shi J, Lu L (2020) Mental health considerations for children quarantined because of COVID-19. Lancet Child Adolesc Health 4 (5):347-349. doi:10.1016/S2352-4642(20)30096-1

7. Yang Y, Li W, Zhang Q, Zhang L, Cheung T, Xiang YT (2020) Mental health services for older adults in China during the COVID-19 outbreak. Lancet Psychiatry 7 (4):e19. doi:10.1016/S2215-0366(20)30079-1

8. Altena E, Baglioni C, Espie CA, Ellis J, Gavriloff D, Holzinger B, Schlarb A, Frase L, Jernelöv S, Riemann D (2020) Dealing with sleep problems during home confinement due to the COVID-19 outbreak: Practical recommendations from a task force of the European CBT-I Academy. J Sleep Res:e13052. doi:10.1111/jsr.13052

9. Purtle J (2020) COVID-19 and mental health equity in the United States. Soc Psychiatry Psychiatr Epidemiol:1-3. doi:10.1007/s00127-020-01896-8

10. Li DJ, Ko NY, Chen YL, Wang PW, Chang YP, Yen CF, Lu WH (2020) COVID-19-Related Factors Associated with Sleep Disturbance and Suicidal Thoughts among the Taiwanese Public: A Facebook Survey. Int J Environ Res Public Health 17 (12). doi:10.3390/ijerph17124479

11. Chenneville T, Schwartz-Mette R (2020) Ethical considerations for psychologists in the time of COVID-19. Am Psychol. doi:10.1037/amp0000661

12. Wang Y, Zhao X, Feng Q, Liu L, Yao Y, Shi J (2020) Psychological assistance during the coronavirus disease 2019 outbreak in China. J Health Psychol 25 (6):733-737. doi:10.1177/1359105320919177

13. Lai J, Ma S, Wang Y, Cai Z, Hu J, Wei N, Wu J, Du H, Chen T, Li R, Tan H, Kang L, Yao L, Huang M, Wang H, Wang G, Liu Z, Hu S (2020) Factors Associated With Mental Health Outcomes Among Health Care Workers Exposed to Coronavirus Disease 2019. JAMA Netw Open 3 (3):e203976.

doi:10.1001/jamanetworkopen.2020.3976

Page 12/16 
14. Kim S, Sinn D, Syn SY (2018) Analysis of College Students' Personal Health Information Activities: Online Survey. J Med Internet Res 20 (4):e132. doi:10.2196/jmir.9391

15. Recabarren RE, Gaillard C, Guillod M, Martin-Soelch C (2019) Short-Term Effects of a Multidimensional Stress Prevention Program on Quality of Life, Well-Being and Psychological Resources. A Randomized Controlled Trial. Front Psychiatry 10:88. doi:10.3389/fpsyt.2019.00088

16. Auerbach RP, Mortier P, Bruffaerts R, Alonso J, Benjet C, Cuijpers P, Demyttenaere K, Ebert DD, Green JG, Hasking P, Murray E, Nock MK, Pinder-Amaker S, Sampson NA, Stein DJ, Vilagut G, Zaslavsky AM, Kessler RC, Collaborators WW-I (2018) WHO World Mental Health Surveys International College Student Project:

Prevalence and distribution of mental disorders. J Abnorm Psychol 127 (7):623-638. doi:10.1037/abn0000362

17. Jenkins PE, Ducker I, Gooding R, James M, Rutter-Eley E (2020) Anxiety and depression in a sample of UK college students: a study of prevalence, comorbidity, and quality of life. J Am Coll Health:1-7. doi:10.1080/07448481.2019.1709474

18. Scanlan JN, Hazelton T (2019) Relationships between job satisfaction, burnout, professional identity and meaningfulness of work activities for occupational therapists working in mental health. Aust Occup Ther $\mathrm{J}$ 66 (5):581-590. doi:10.1111/1440-1630.12596

19. Beiter R, Nash R, McCrady M, Rhoades D, Linscomb M, Clarahan M, Sammut S (2015) The prevalence and correlates of depression, anxiety, and stress in a sample of college students. J Affect Disord 173:90-96. doi:10.1016/j.jad.2014.10.054

20. Lew B, Osman A, Huen JMY, Siau CS, Talib MA, Cunxian J, Chan CMH, Leung ANM (2020) A comparison between American and Chinese college students on suicide-related behavior parameters. Int $\mathrm{J}$ Clin Health Psychol 20 (2):108-117. doi:10.1016/j.ijchp.2020.03.005

21. Kanadiya MK, Sallar AM (2011) Preventive behaviors, beliefs, and anxieties in relation to the swine flu outbreak among college students aged 18-24 years. Z Gesundh Wiss 19 (2):139-145. doi:10.1007/s10389010-0373-3

22. Main A, Zhou Q, Ma Y, Luecken LJ, Liu X (2011) Relations of SARS-related stressors and coping to Chinese college students' psychological adjustment during the 2003 Beijing SARS epidemic. J Couns Psychol 58 (3):410-423. doi:10.1037/a0023632

23. Cao W, Fang Z, Hou G, Han M, Xu X, Dong J, Zheng J (2020) The psychological impact of the COVID-19 epidemic on college students in China. Psychiatry Res 287:112934. doi:10.1016/j.psychres.2020.112934

24. Al-Rabiaah A, Temsah MH, Al-Eyadhy AA, Hasan GM, Al-Zamil F, Al-Subaie S, Alsohime F, Jamal A, Alhaboob A, Al-Saadi B, Somily AM (2020) Middle East Respiratory Syndrome-Corona Virus (MERS-CoV) associated stress among medical students at a university teaching hospital in Saudi Arabia. J Infect Public Health. doi:10.1016/j.jiph.2020.01.005

25. Wong JG, Cheung EP, Cheung V, Cheung C, Chan MT, Chua SE, McAlonan GM, Tsang KW, Ip MS (2004) Psychological responses to the SARS outbreak in healthcare students in Hong Kong. Med Teach 26 (7):657659. doi:10.1080/01421590400006572

26. Prime $\mathrm{H}$, Wade M, Browne DT (2020) Risk and resilience in family well-being during the COVID-19 pandemic. Am Psychol. doi:10.1037/amp0000660

27. Spitzer RL, Kroenke K, Williams JB (1999) Validation and utility of a self-report version of PRIME-MD: the PHQ primary care study. Primary Care Evaluation of Mental Disorders. Patient Health Questionnaire. JAMA 
282 (18):1737-1744. doi:10.1001/jama.282.18.1737

28. Spitzer RL, Kroenke K, Williams JB, Lowe B (2006) A brief measure for assessing generalized anxiety disorder: the GAD-7. Arch Intern Med 166 (10):1092-1097. doi:10.1001/archinte.166.10.1092

29. Auerbach RP, Alonso J, Axinn WG, Cuijpers P, Ebert DD, Green JG, Hwang I, Kessler RC, Liu H, Mortier P, Nock MK, Pinder-Amaker S, Sampson NA, Aguilar-Gaxiola S, Al-Hamzawi A, Andrade LH, Benjet C, Caldas-deAlmeida JM, Demyttenaere K, Florescu S, de Girolamo G, Gureje O, Haro JM, Karam EG, Kiejna A, KovessMasfety V, Lee S, McGrath JJ, O'Neill S, Pennell BE, Scott K, Ten Have M, Torres Y, Zaslavsky AM, Zarkov Z, Bruffaerts R (2016) Mental disorders among college students in the World Health Organization World Mental Health Surveys. Psychol Med 46 (14):2955-2970. doi:10.1017/S0033291716001665

30. Lei XY, Xiao LM, Liu YN, Li YM (2016) Prevalence of Depression among Chinese University Students: A MetaAnalysis. PLoS One 11 (4):e0153454. doi:10.1371/journal.pone.0153454

31. Eisenberg D, Hunt J, Speer N (2013) Mental health in American colleges and universities: variation across student subgroups and across campuses. J Nerv Ment Dis 201 (1):60-67.

doi:10.1097/NMD.0b013e31827ab077

32. Othman N, Ahmad F, El Morr C, Ritvo P (2019) Perceived impact of contextual determinants on depression, anxiety and stress: a survey with university students. Int J Ment Health Syst 13:17. doi:10.1186/s13033-0190275-x

33. KawohI W, Nordt C (2020) COVID-19, unemployment, and suicide. Lancet Psychiatry 7 (5):389-390. doi:10.1016/s2215-0366(20)30141-3

34. Bryan CJ, Bryan AO, Baker JC (2020) Associations among state-level physical distancing measures and suicidal thoughts and behaviors among U.S. adults during the early COVID-19 pandemic. Suicide Life Threat Behav. doi:10.1111/sltb.12653

35. Gater R, Tansella M, Korten A, Tiemens BG, Mavreas VG, Olatawura MO (1998) Sex differences in the prevalence and detection of depressive and anxiety disorders in general health care settings: report from the World Health Organization Collaborative Study on Psychological Problems in General Health Care. Arch Gen Psychiatry 55 (5):405-413. doi:10.1001/archpsyc.55.5.405

36. L. LLLHM (2006) A Survey on University Students' Suicidal Ideation and the Influence Factors. Journal of Northwest University (Philosophy and Social ences Edition)

37. Hamilton TK, Schweitzer RD (2000) The cost of being perfect: perfectionism and suicide ideation in university students. Aust N Z J Psychiatry 34 (5):829-835. doi:10.1080/j.1440-1614.2000.00801.x

38. Silverman MM, Meyer PM, Sloane F, Raffel M, Pratt DM (1997) The Big Ten Student Suicide Study: a 10-year study of suicides on midwestern university campuses. Suicide Life Threat Behav 27 (3):285-303

39. Gariepy G, Honkaniemi H, Quesnel-Vallee A (2016) Social support and protection from depression: systematic review of current findings in Western countries. Br J Psychiatry 209 (4):284-293.

doi:10.1192/bjp.bp.115.169094

40. van Harmelen AL, Gibson JL, St Clair MC, Owens M, Brodbeck J, Dunn V, Lewis G, Croudace T, Jones PB, Kievit RA, Goodyer IM (2016) Friendships and Family Support Reduce Subsequent Depressive Symptoms in At-Risk Adolescents. PLoS One 11 (5):e0153715. doi:10.1371/journal.pone.0153715

41. Crockett LJ, Iturbide MI, Torres Stone RA, McGinley M, Raffaelli M, Carlo G (2007) Acculturative stress, social support, and coping: relations to psychological adjustment among Mexican American college students.

Cultur Divers Ethnic Minor Psychol 13 (4):347-355. doi:10.1037/1099-9809.13.4.347

Page $14 / 16$ 
42. Pruitt LD, Mclntosh LS, Reger G (2020) Suicide Safety Planning During a Pandemic: The Implications of COVID-19 on Coping with a Crisis. Suicide Life Threat Behav 50 (3):741-749. doi:10.1111/sltb.12641

43. Fernandez-Rouco N, Carcedo RJ, Lopez F, Orgaz MB (2019) Mental Health and Proximal Stressors in Transgender Men and Women. J Clin Med 8 (3). doi:10.3390/jcm8030413

44. Elizarraras-Rivas J, Vargas-Mendoza JE, Mayoral-Garcia M, Matadamas-Zarate C, Elizarraras-Cruz A, Taylor M, Agho K (2010) Psychological response of family members of patients hospitalised for influenza A/H1N1 in Oaxaca, Mexico. BMC Psychiatry 10:104. doi:10.1186/1471-244X-10-104

45. Oboho IK, Tomczyk SM, Al-Asmari AM, Banjar AA, Al-Mugti H, Aloraini MS, Alkhaldi KZ, Almohammadi EL, Alraddadi BM, Gerber SI, Swerdlow DL, Watson JT, Madani TA (2015) 2014 MERS-CoV outbreak in Jeddah--a link to health care facilities. N Engl J Med 372 (9):846-854. doi:10.1056/NEJMoa1408636

46. Khan A, Farooqui A, Guan Y, Kelvin DJ (2015) Lessons to learn from MERS-CoV outbreak in South Korea. The Journal of Infection in Developing Countries 9 (06):543-546. doi:10.3855/jidc.7278

47. Zhong BL, Luo W, Li HM, Zhang QQ, Liu XG, Li WT, Li Y (2020) Knowledge, attitudes, and practices towards COVID-19 among Chinese residents during the rapid rise period of the COVID-19 outbreak: a quick online cross-sectional survey. Int J Biol Sci 16 (10):1745-1752. doi:10.7150/ijbs.45221

48. Ren SY, Gao RD, Chen YL (2020) Fear can be more harmful than the severe acute respiratory syndrome coronavirus 2 in controlling the corona virus disease 2019 epidemic. World J Clin Cases 8 (4):652-657. doi:10.12998/wjcc.v8.i4.652

49. Wang C, Pan R, Wan X, Tan Y, Xu L, Ho CS, Ho RC (2020) Immediate Psychological Responses and Associated Factors during the Initial Stage of the 2019 Coronavirus Disease (COVID-19) Epidemic among the General Population in China. Int J Environ Res Public Health 17 (5). doi:10.3390/ijerph17051729

50. Xiang YT, Yang Y, Li W, Zhang L, Zhang Q, Cheung T, Ng CH (2020) Timely mental health care for the 2019 novel coronavirus outbreak is urgently needed. Lancet Psychiatry 7 (3):228-229. doi:10.1016/S22150366(20)30046-8

51. Leung GM, Lam TH, Ho LM, Ho SY, Chan BH, Wong IO, Hedley AJ (2003) The impact of community psychological responses on outbreak control for severe acute respiratory syndrome in Hong Kong. J Epidemiol Community Health 57 (11):857-863. doi:10.1136/jech.57.11.857

52. Shigemura J, Ursano RJ, Morganstein JC, Kurosawa M, Benedek DM (2020) Public responses to the novel 2019 coronavirus (2019-nCoV) in Japan: Mental health consequences and target populations. Psychiatry Clin Neurosci. doi:10.1111/pcn.12988

53. Gostic K, Gomez AC, Mummah RO, Kucharski AJ, Lloyd-Smith JO (2020) Estimated effectiveness of symptom and risk screening to prevent the spread of COVID-19. Elife 9. doi:10.7554/eLife.55570

54. China. NHCotPsRo (2020) Technical Guide for Prevention and Control of New Coronavirus Infection in Medical Institutions (Second Edition).

www.nhc.gov.cn/jkj/s3577/202001/c67cfe29ecf1470e8c7fc47d3b751e88.shtml. Accessed 19 February 2020

55. Liao Q, Cowling BJ, Lam WW, Ng DM, Fielding R (2014) Anxiety, worry and cognitive risk estimate in relation to protective behaviors during the 2009 influenza A/H1N1 pandemic in Hong Kong: ten cross-sectional surveys. BMC Infect Dis 14:169. doi:10.1186/1471-2334-14-169

56. Xi JP (2020) the resumption of work, production and education.

http://news.cnr.cn/native/gd/20200509/t20200509_525082726.shtml

Page 15/16 
57. China (2020) Circular of the general office of the national health commission on Internet diagnosis, treatment and consultation services in epidemic prevention and control. doi:http://www.nhc.gov.cn/cmssearch/xxgk/getManuscriptXxgk.htm?id=ec5e345814e744398c2adef17b657fb8 